\title{
Study on College Sports Culture and Curriculum Construction under the Theory of Green Sports
}

\author{
Shunjia Bi \\ Zhuhai College of Jilin University \\ cpcimeici2018@163.com
}

Keywords: Green sports; College sports culture; Teaching method; Curriculum construction

\begin{abstract}
Objective To explore the methods of college sports culture and curriculum construction under the theory of green sports. Methods The literature analysis method and inductive analysis method were used to analyze the construction of college sports culture system and curriculum construction methods under the green sports theory, and put forward development opinions. Results The results show that under the vision of green proposal theory, there are problems in college physical education curriculum, including teaching model, ground materials and teacher team structure. Conclusion Under the guidance of the concept of green development in the new era, the concept of sports culture construction in colleges should update the old sports values. People should be oriented and the concept of ecological sports should be vigorously advocated, and harmonious development is achieved while reaching the goal of physical education in colleges and universities; the culture of college sports system is improved and various sports activities are organized earnestly to improve the level of physical education and promote the scientific management of sports culture; under the guidance of green thinking and green lifestyle, advance with the times to develop the physical culture of college sports, so that the campus environment is better, making the teachers and students healthier. The realization of college education goals has more long-term social value. The concept of green sports is infiltrated in college physical education, following the harmonious development of human and nature, the harmonious development of people and the harmonious development of human beings, and finally achieving the harmonious development of students' mind and body, thus achieving the coordination of personality cultivation and humanity cultivation.

The origin and development of sports is essentially a history of green sports development. Green sports are produced for the better development of human beings and the harmonious development of society. It takes the idea of comprehensive and coordinated development of society to achieve harmony between man and nature. Therefore, green sports can also be called harmonious sports. It advocates a healthy, harmonious and civilized lifestyle to promote the harmonious development of society.
\end{abstract}

\section{Green Development Concept and College Sports Culture}

Green is the main color of nature. Green is a symbol of harmony in nature. It is a symbol of life, exuberant vitality. The connotation of green sports can be understood as: sports has no pollution, and it's fair, pure, scientific, progressive, humanized and united. It makes proposal and creates for the harmony, civilization, peace and development of society, and make it produce positive results. The essence of green sports is to achieve the overall dynamic harmony between man and nature, man to man, and man himself through the idea and means of comprehensive and coordinated development of sports. This is the common goal of modern sports, and it is the source and driving force for the sustainable development of human sports. ${ }^{[1]}$

Practice the Concept of Green Development, and comprehensively Build a Sports System Culture

As an important part of the scientific development concept in the new era, the concept of green 
development needs support from various aspects such as science and technology, capital and system. System support is especially important to implement the concept of green development and build a scientific and sound sports culture system. Only a scientific and rational system can guarantee the standardization of sports and cultural activities, and can meet the requirements of organic combination of green and development, and common development of people and nature. The comprehensive construction of sports system culture includes three aspects: leadership system, organizational structure and management system:

(1) Leadership system

In the institutional culture, the leadership system affects the setting of the organization structure and restricts all aspects of the management of sports culture activities. Therefore, leadership system is the core content of institutional culture. The sports culture leadership system is the general term for leadership style, leadership structure and leadership system, where the leadership system is the core part. The design of sports culture leadership system of each university is restricted by the overall strength of the university and various other factors. The difference and individuality exist objectively. However, like the design of various other social, political and economic systems, the green development concept must be regarded as the basic factor and important consideration for design. ${ }^{[2]}$

It requires the establishment of a strong sports culture leadership system to implement the concept of green development, which generally needs the main leaders of the party and government in colleges and universities to be responsible for ensuring the systematic construction and smooth implementation of the system culture. Under the strong leadership of the core, universities should also rationally design leadership level and leadership span. The choice of leadership level and leadership span can be based on the management level and scope of the existing trade unions and student management systems in each university, and then scientifically adjusted according to specific sports and cultural activities, allowing the five functions of decision-making, consultation, implementation, supervision and information feedback operated systematically and relatively independently in the process of sports culture construction. ${ }^{[3]}$ The establishment of sports culture leadership system of various universities is the premise that all sports culture activities follow a clear management level, hierarchical sequence, chain of command and communication channels, and the implementation of standardization and normalization still needs scientific organizational structure and sound management system support.

(2) Organizational structure

Colleges and universities must establish a special department or organization and design a reasonable organizational structure to carry out sports culture-related activities to practice the concept of green development and construct sports system culture. The organizational structure of college sports culture refers to the mutual relationship and contact between various departments within the university. It includes two basic relationships: one is the vertical relationship, that is, the subordinate leadership relationship; the other is the horizontal relationship, that is, the parallel cooperation between various departments. The design of the organizational structure of college sports culture must consider these two kinds of relationships comprehensively, and establish an organizational structure with clear functions and high efficiency. This kind of organizational structure needs to establish a special department that is responsible for sports cultural function or distribute the management tasks of specific decision-making, plan and scheme to the individuals based on the original physical education, trade union affairs, and student management system. In the course of work, the functional departments or the staff members who undertake the tasks should pay attention to the leading role of green development concept in the construction of sports culture, and carry out the sports cultural activities of the universities correctly, scientifically and reasonably in the normal daily work. In each link, the concept of green development is infiltrated, and as the leading work, the construction of college sports culture can adapt to the current situation. On this basis, the establishment of an efficient college sports culture construction mechanism will enable the activities of sports culture construction to be carried out in an orderly manner. ${ }^{[4]}$ 


\section{(3) Management system}

The college sports culture management system refers to the sum of the normative forms on which the organization, control, coordination, feedback and other activities adopted to achieve the management objectives. It's the institutionalized results of management norms. The management of sports culture under the guidance of the concept of green development must have scientific, rational and full-fledged arrangements in the construction of management ideas, management organizations, management talents, management methods, management methods and other systems. ${ }^{[5]}$ Specifically, it is necessary to formulate comprehensive regulations, such as relevant sports competition systems, sports evaluation systems, sports excellence reward systems, and campus sports activities on the basis of considering the important factors such as campus environment, school development goals, and the ideological and cultural qualities of teachers and students. such as regulations. These regulations must reflect the connotation of green development and ecological sports, comprehensively consider the interests of students, the interests of schools and the long-term interests of the society, which is the basis to establish an efficient, harmonious campus sports culture with sustainable development.

\section{The Problems that should be Paid Attention to in College Physical Education under the Guidance of the Concept of Green Sports}

(1) To grasp the guiding ideology of "all-round coordinated development" of green sports, China's higher physical education in the $21^{\text {st }}$ century must cultivate compound talents with high-quality and all-round development

The college physical education under the concept of green sports is to permeate the concept of green sports in physical education, infiltrate the green concept teaching in the physical education classroom, cultivate students' green consciousness, thus promote the harmonious development of students' mind and body, and realize the coordination and symbiosis of personality training and humanity cultivation. [6] After leaving the campus and going to the society, college students are the backbone of social construction. If their green awareness are not cultivated, it will be difficult to be competent in building socialism. Therefore, strengthening the green concept in colleges and universities can help students to establish a correct world outlook, outlook on life and values. It is not only the requirement of human society, but also the requirement of students themselves, and the guarantee of sustainable development of human beings. ${ }^{[7]}$

(2) Following the idea of harmonious development between man and nature, the education of students' green sports awareness should be strengthened in college physical education

The concept of green sports shows that the development of society must be sustainable if human beings want to establish a harmonious and equal relationship with nature. Not only the contemporary people need to be considered, but also the next generation. ${ }^{[8]}$ Therefore, it is necessary for us to use the important carrier of college physical education to help each college student establish a green sports concept, infiltrate certain environmental education in physical education and fully cultivate students' awareness of environmental protection. For example, in the absence of sufficient sports venues, the natural environment can be used to build sports venues, so that students can complete physical exercise in natural green venues; students should be taught to care for sports equipment and carry out regular maintenance; all harmful products are rejected to go to sports venues to ensure that students can learn and exercise in a green, environmentally friendly and healthy sports environment. ${ }^{[9]}$

(3) Emphasizing the concept of harmony between people and establishing a new type of teacher-student relationship

The traditional teaching mode places teachers in an authoritative position and students in a passive position, completely ignoring the students' personality and interest. The teacher-student relationship under the concept of green sports is an active cooperative relationship based on equality, respect, democracy and understanding. This kind of cooperative relationship should be harmonious, two-way, 
coordinated and active, rather than the obeying and command relationship. Teachers are no longer leaders but helpers and guides, and they are equal friends in the sense of personality. This new type of teacher-student relationship will motivate students' creative interest from time to time, and improve their creative ability in the process of innovation activities. ${ }^{[10]}$

(4) Paying attention to the harmonious development of people themselves and earnestly improving the quality of physical education teachers in colleges and universities. Human's self-harmony includes the harmony of physical, psychological and physical and mental aspects. Green sports can make sports participants perfect in body and mind, body posture and have sound personality, thus achieving perfect harmony. The harmony advocated by green sports provides an ideal way for people's own harmonious development, which essentially solves the problem of human development. Green sports not only makes the participating athletes muscular, well-balanced, and alert, but also makes their psychological quality sound and social morality good.

\section{Conclusion}

Under the guidance of the concept of green development in the new era, the concept of sports culture construction in colleges should update the old sports values. People should be oriented and the concept of ecological sports should be vigorously advocated, and harmonious development is achieved while reaching the goal of physical education in colleges and universities; the culture of college sports system is improved and various sports activities are organized earnestly to improve the level of physical education and promote the scientific management of sports culture; under the guidance of green thinking and green lifestyle, advance with the times to develop the physical culture of college sports, so that the campus environment is better, making the teachers and students healthier. The realization of college education goals has more long-term social value. The concept of green sports is infiltrated in college physical education, following the harmonious development of human and nature, the harmonious development of people and the harmonious development of human beings, and finally achieving the harmonious development of students' mind and body, thus achieving the coordination of personality cultivation and humanity cultivation.

\section{References}

[1] Hu Angang, Zhou Shaojie. Green Development: Functional Definition, Mechanism Analysis and Development Strategy [J]. China Population, Resources and Environment, 2014, 24(1): 14-20.

[2] Lu Jia, Hao Lina. Development of Sports Culture Construction in colleges and Universities from the Perspective of Sports Powers[J]. Sports, 2016, 12: 34-35.

[3] He Bin, Luo Xianglin. Review and Reflection on the Study of Sports Culture in China since the Reform and Opening-up[J]. Journal of Tianjin Institute of Physical Education,2010,25(6):522-525.

[4] Gong Jianlin. Ecological Sports in the Perspective of Ecological Civilization[J]. Journal of Physical Education, 2008, 15(7): 20-23.

[5] Zhang Hongtan. Study on Basic Theory of Sports [M]. Guilin: Guangxi Normal University Press, 2004: 22-26.

[6] Tan Jinfei, Fan Ying. Quality Requirements of Physical Education Teachers under the View of Green Sports[J]. Journal of Hunan Agricultural University: Social Science Edition,2008(4):126-127.

[7] Zhou Hongfu,Wu Bo.Thoughts on the Teaching of Physical Education and Health under the View of Green Sports[J].Journal of Physical Education Institute of Shanxi Teachers University,2007(2):77-79.

[8]Xu Benli. Reflections on Several Hot Issues in College Physical Education in China in the $21^{\text {st }}$ Century[J].Sports Science Research,2005(1):79-82. 
[9]Zhou Aiguang. Examining the Status and Role of the Government from the Concept of Sports Public Service[J].Sport Science,2012,32(5):64-70.

[10] Xiao Mouwen. From Functional Deduction to Institutional Change: The Evolution of China's Sports Policy after Reform and Opening-up[J]. Journal of Beijing Sport University, 2012(2): 16-18. 